\title{
Growth and functionalization of carbon nanotubes on quartz filter for environmental applications
}

\author{
Roger Amade*, Shahzad Hussain, Ismael R. Ocaña and Enric Bertran \\ *Correspondence: r.amade@ub.edu

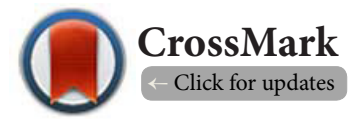 \\ Department of Applied Physics and Optics, FEMAN Group, IN²UB, University of Barcelona, Barcelona, Spain.
}

\begin{abstract}
Background: Air pollution has become an important issue worldwide due to its adverse health effects. Among the different air contaminants, volatile organic compounds (VOCs) are liquids or solids with a high vapor pressure at room temperature that are extremely dangerous for human health. Removal of these compounds can be achieved using nanomaterials with tailored properties such as carbon nanotubes.

Methods: Vertically-aligned multiwall carbon nanotubes (CNTs) were successfully grown on quartz filters by means of plasma enhanced chemical vapor deposition (PECVD). Furthermore, a plasma treatment was performed in order to modify the surface properties of the CNTs. The adsorption/desorption processes of three chlorinated compounds (trichloroethylene, 1,2-dichlorobenzene and chloroform) on the CNTs were studied using mass spectrometry measurements with a residual gas analyzer.

Results: The adsorption capability of the CNTs increased after functionalization of their surface with a water plasma treatment. In addition, it was found that the presence of aromatic rings, water solubility and polarity of the VOCs play an important role on the adsorption/desorption kinetics at the CNTs surface.

Conclusions: This study demonstrates the applicability of CNTs deposited on quartz filters for the removal or selective detection of volatile organic compounds (VOCs). The presence of aromatic rings in VOCs results in $\pi$-stacking interactions with a significant increase of their adsorption. On the other hand, it was found that CNTs surface interactions increase with water solubility and polarity of the VOC.
\end{abstract}

Keywords: Volatile organic compounds, carbon nanotubes, adsorption, air pollution

\section{Background}

A large number of households and industrials products contain volatile organic compounds (VOCs). VOCs can easily evaporate at room temperature and are extremely harmful for the health of human beings. Among various types of VOCs, chlorinated compounds are used frequently in a wide range of industrial products and chemical processes, polluting the environment and ground water resources. Therefore, it is desirable to control the chlorinated VOCs emission in air by utilizing various kinds of adsorption/removal processes.

Carbon nanotubes (CNTs) [1] are based in a unique material that possesses high mechanical strength, ballistic conduction, high temperature thermal stability and high surface area [2-5]. All these extraordinary properties make them a useful material for various kinds of applications such as supercapacitors [6,7], sensors [8], field emitters [9] and for the removal of contaminants from water and gases $[10,11]$.

Usually, carbon based adsorbents are used for the removal of contaminants due to their high surface area. The surface area of CNTs is in the range of $150-3000 \mathrm{~m}^{2} / \mathrm{g}$ [5], which is comparable to other carbon based adsorbents. CNTs have been shown to be an efficient adsorbent for the elimination of dibenzo-p-dioxin from contaminant water [12]. Also, they can adsorb a variety of gases and have been proven to be superior to activated carbon for the removal of dioxin1,2-dichlorobenzene from water in a wide range of $\mathrm{pH}(3-10)[11,13]$. Recently, X Ma et al., [14] have shown the adsorption/desorption of chlorinated compounds by pristine and thermally treated multi-walled carbon nanotubes. A number of features provide CNTs with superior adsorption properties than activated carbon; well defined structure, interstitial region between nanotubes in the bundles, grooves, curved surface outside of nanotube bundles, defect sites and, if the caps of nanotubes are open, the inner surface of tube. Several investigations can be found in the literature, which have shown that CNTs are more effective adsorbents for organic molecules compared to activated carbon $[15,16]$.

The characteristics of CNTs suggest that they have strong interaction with organic molecules through non-covalent forces, hydrogen bonds, $\pi-\pi$ interactions in, for instance, polycyclic aromatic hydrocarbons (PAHs) [17], electrostatic forces and van der Waals forces. The main interactions responsible for the adsorptions of organic compounds by CNTs are: hydrophobic effect, $\pi$-electron donor-acceptor ( $\pi$-EDA) bonds and hydrogen bonds [18-20]. Multilayer adsorption may also occur when 
organic chemicals are adsorbed on the surface of CNTs [21]. In addition, it has been shown that CNTs display faster desorption for a wide range of nonpolar compounds $[22,23]$.

Generally, amorphous carbon and catalyst particles are also present on the surface of the as grown CNTs, which can significantly decrease the adsorption and desorption efficiency of the CNTs by blocking their pores [24]. The removal of amorphous carbon is usually achieved by heating the CNTs at $300-500^{\circ} \mathrm{C}$ and the catalyst particles can be eliminated by acid treatment [25]. This treatment results in the destruction of the structure and introduction of carboxylic groups in CNTs. Furthermore, it is rather difficult to control and very harsh for the graphitic walls of CNTs [25-27]. Our previous studies show that the CNTs surface can be cleaned and crafted with different functional groups by controlling the conditions of a plasma treatment ( $\mathrm{rf}$ plasma power, gas composition and pressure) $[\mathbf{2 8 , 2 9 ] .}$.

CNTs can be grown on various kinds of substrates such as $\mathrm{Si}$ [30], $\mathrm{Cu}$ [31], microelectrode arrays (MEAs) [32], carbon fiber [33] and quartz [34]. Recently, Li et al., published the growth of CNTs on quartz fiber filters using a floating catalyst chemical vapour deposition method, and used them for filtration of sub-micron aerosols [35]. In the present work, vertically-aligned multiwall carbon nanotubes (VA-MWCNTs) were grown on quartz filters by plasma-enhanced chemical vapor deposition (PECVD). A water plasma treatment was performed on the as grown CNTs to remove the amorphous carbon, increase the defect sites and to preferentially introduce different kinds of oxygen functional groups [28]. Introduction of oxygen groups on the surface of CNTs through a water plasma treatment makes them more hydrophilic and allows us to increase the interactions with VOCs. Surface functional groups such as carboxyl groups facilitate the formation of stronger $\pi-\pi$ bonds between CNTs and aromatic molecules [36]. The hydroxyl groups can form hydrogen bonds with electronegative atoms, typically F, $\mathrm{O}$ and $\mathrm{N}$. Moreover, hydrogen atoms attached to a carbon atom can also participate in hydrogen bonding when the carbon atom is bounded to electronegative atoms, like in the case of chloroform $\left(\mathrm{CHCl}_{3}\right)$.

Herein, the adsorption/desorption properties of chlorinated VOCs on quartz filter (QF), carbon nanotubes grown on QF (CNTsQF) and water plasma treated CNTsQF (wp-CNTsQF) have been investigated.

\section{Methods}

\section{Synthesis and functionalization of VAMWCNTs}

VA-MWCNTs were grown on quartz filters by using radiofrequency plasma-enhanced chemical vapour deposition (rf-PECVD). A detailed description of the growth process and reactor used can be found elsewhere [7]. A summary of the growth conditions is given in Table 1. Unlike our previous works [7], high-purity quartz $\left(\mathrm{SiO}_{2}\right)$ microfiber filters (Whatman ${ }^{\mathrm{tm}}$, UK) were used as substrates for the growth of CNTs. These quartz filters have $47 \mathrm{~mm}$ of diameter, $450 \mu \mathrm{m}$ thickness and they are formed by long fibers having a diameter below 1.5 $\mu \mathrm{m}$. Briefly, a thin layer of $3 \mathrm{~nm}$ Fe catalyst was deposited by rf-magnetron sputtering on a quartz filter and annealed at $680^{\circ} \mathrm{C}$ during $120 \mathrm{~s}$ (ramp time: $750 \mathrm{~s}$ ) in hydrogen atmosphere to obtain Fe nanoislands. Then, the precursor gas $\left(\mathrm{NH}_{3^{\prime}} 100\right.$ $\mathrm{sccm})$ and the carbon source $\left(\mathrm{C}_{2} \mathrm{H}_{2}, 50 \mathrm{sccm}\right)$ are allowed to enter the reaction chamber and the PECVD reaction takes place with the formation of CNTs at a constant pressure of $100 \mathrm{~Pa}$.

Table 1. Summary of the VA-MWCNTs growth conditions.

\begin{tabular}{ll}
\hline Parameter & Value \\
\hline Catalyst layer thickness & $3 \mathrm{~nm}$ \\
Annealing time & $870 \mathrm{~s}$ \\
PECVD process temperature & $700^{\circ} \mathrm{C}, 730^{\circ} \mathrm{C}$ \\
PECVD process plasma power & $50 \mathrm{~W}$ \\
PECVD process time & $900 \mathrm{~s}, 1800 \mathrm{~s}$ \\
\hline
\end{tabular}

In a further step some of the samples were treated with water plasma to remove amorphous carbon and introduce oxygen groups on the CNTs surface. The CNTs were treated with 10 W rf power and $135 \mathrm{~Pa}$ water pressure for $120 \mathrm{~s}$, which is only specific to the removal of amorphous carbon and the introduction of different oxygen containing functional groups, without destroying the nanotubes [28].

\section{Volatile organic compounds}

The adsorption/desorption properties of CNTs were studied using three chlorinated VOCs; trichloroethylene, chloroform and 1,2-dichlorobenzene. The chemicals were from high purity (99.9\%, Sigma-Aldrich) and were used undiluted.

\section{Adsorption studies}

A system was devised to study the adsorption of volatile organic compounds by CNTs-based filters (see Figure 1). The system has three channels made of a stainless steel tube with an internal diameter of $4 \mathrm{~mm}$ and an external diameter of $6.32 \mathrm{~mm}$. A flask containing the chlorinated compound to be studied is placed at the start of the central channel, and is connected to a three-way valve. Both left and right channels have a filter holder at the end, where the carbon nanotubes filter is placed. The whole system is connected to a turbomolecular pump, which allows operation under high vacuum conditions $\left(10^{-5} \mathrm{~Pa}\right)$ and all experiments were carried out at room temperature.

A filter without carbon nanotubes is placed in the right channel and is taken as a reference. In the left channel different types of carbon nanotube filters are placed and systematically analyzed (untreated CNTs and wp-treated CNTs). In order to perform the measurements, a LabVIEW program controls the opening of the pneumatic valves present at the entrance of 


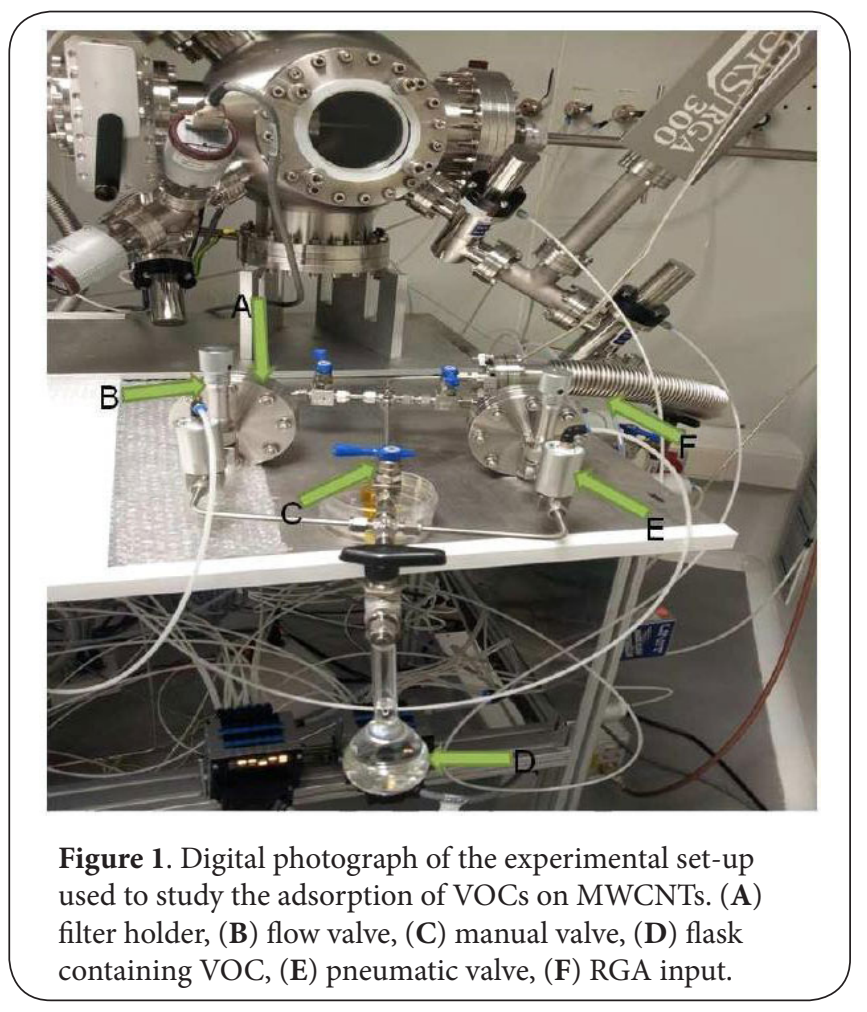

each channel during a period of $50 \mathrm{~ms}$, letting the chlorinated compound flow through the filter under study.

Immediately after opening the valves, the RGA detects a fast increase of the partial pressures of the species followed by a slower decrease related to adsorption and desorption processes. The partial pressure of the compounds can be related to the concentration of the chemical species in the gas phase. Therefore, we can get an idea about the kinetics of the adsorption/desorption processes that occur at the surface of the different CNTs-based filters by representing the partial pressure versus time in a semi-logarithmic scale. Since the adsorption process was too fast to be analyzed with our setup, we studied the desorption curves of the different compounds. The measurements could be fitted with a double exponential equation (1), which indicates the presence of two desorption processes. Depending on the interactions between VOC and filter, only one of the two mechanisms was observed. In those cases, a simple exponential equation was used.

$$
P(t)=P_{R}+P_{1} \exp \left[-\left(t-t_{0}\right) / \tau_{1}\right]+P_{0} \exp \left[-\left(t-\tau_{0}\right) / \tau_{2}\right]
$$

Where $P_{1}$ and $P_{2}$ are partial pressures in $\mathrm{Pa}, P_{R}$ is the residual pressure in $\mathrm{Pa}, t$ is the time in $s, t_{0}$ the initial time of desorption process in $\mathrm{s}, \mathrm{\tau}_{1}$ and $\mathrm{\tau}_{2}$ are the characteristic times in $\mathrm{s}$.

\section{Characterization techniques}

Field emission scanning electron microscopy (FESEM) (Hitachi S-4100, Japan) and high resolution transmission electron microscopy (HRTEM) (JEOL JEM-2100, Japan) were used for the morphological and structural characterization of CNTs.

RAMAN spectroscopy was performed to evaluate the quality of the CNTs using a micro-Raman system (Horiba LabRam HR800, Japan). A green laser of wavelength $532 \mathrm{~nm}$, $0.25 \mathrm{~mW}$ power and a 100X objective were used during the measurements. Quadruple mass spectroscopy-residual gas analyzer (SRS QMS-RGA-300, USA) was used to analyze the partial pressure of the chemical species that passed through the filter.

\section{Results and discussion Morphological characterization}

In order to increase the VOCs adsorption capacity of the quartz filters, a large surface area is needed, which can be achieved by growing long CNTs on top of them with a high surface density. Based on our experience in growing CNTs on c-Si wafer, growth conditions were chosen close to the optimum ones previously obtained [7]. Here, the substrate is a $\mathrm{SiO}_{2}$ filter with the same chemical composition as the native $\mathrm{SiO}_{2}$ present on a silicon wafer. Thus, we expect that similar conditions will provide the growth of CNTs on quartz filters. However, in the present work, the surface is not flat, but rather a 3D matrix of quartz microfibers, which can affect the nucleation of catalyst particles and as a consequence the CNTs structure and morphology.

(Figure 2a) shows CNTs grown on QF at an annealing temperature of $680^{\circ} \mathrm{C}$, a growth temperature of $700^{\circ} \mathrm{C}$ and growth time of $15 \mathrm{~min}$. Under these conditions the CNTs were not vertically aligned and their density was also not very high. (Figure 2b) shows a SEM image of CNTs grown at a higher growth temperature $\left(730^{\circ} \mathrm{C}\right)$ and longer deposition time (30 $\mathrm{min})$. The density of CNTs increases significantly with respect to those grown at $700^{\circ} \mathrm{C}$ and they are vertically aligned in all directions of the quartz fibers. Therefore, these conditions are more suitable for the growth of CNTs on quartz filters and with a high surface area.

(Figure 2c) shows wp-treated CNTsQF at an rf power of 10 $\mathrm{W}$ and $135 \mathrm{~Pa}$ water pressure. Most of the amorphous carbon is removed while keeping the alignment and a difference in texture can be appreciated in comparison to untreated CNTs. TEM analysis of untreated MWCNTs clearly show their "bamboo"-like structure, as well as the amorphous carbon on the surface and Fe catalyst particles on the tips of CNTs (Figure 2d).

\section{Raman spectroscopy}

Analysis of MWCNTs Raman spectra is usually performed by interpreting the relation between two well-known bands; $D$ and $\mathrm{G}$, located at $\sim 1350 \mathrm{~cm}^{-1}$ and $\sim 1580 \mathrm{~cm}^{-1}$, respectively [37]. $\mathrm{D}$ band is a double resonance mode and its appearance is due to the existence of amorphous carbon, structural disorder and defects caused by pentagons or heptagons on the nanotubes $[38,39]$. $G$ band is the tangential stretching mode of sp2 

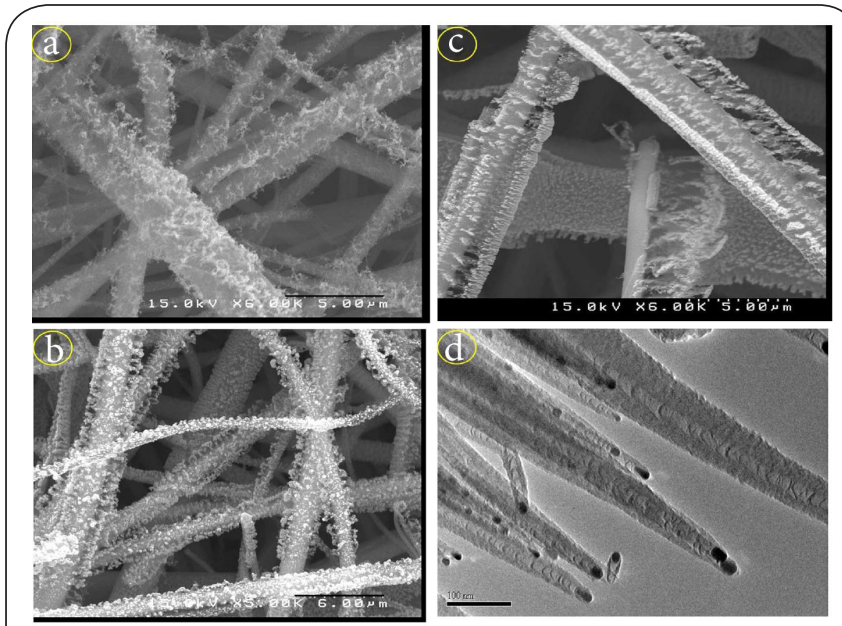

Figure 2. SEM images of CNTs grown on quartz filter (a) at $700^{\circ} \mathrm{C}$ for $15 \mathrm{~min}$ and $(\mathbf{b})$ at $730^{\circ} \mathrm{C}$ for $30 \mathrm{~min}$. (c) wp-treated $\mathrm{CNTsQF}$ at $10 \mathrm{~W}$ plasma power and $135 \mathrm{~Pa}$ pressure.

(d) HRTEM image of untreated CNTs on quartz filter.

bonded carbon atoms in graphene-like structures. Analysis of the ratio between the $D$ and $G$ band intensities $\left(I_{D} / I_{G}\right)$ gives us information about structural disorder.

(Figure 3) shows Raman spectra of CNTsQF and wp-CNTsQF. The fitting process was improved by the introduction of two additional bands; I band at $1210 \mathrm{~cm}^{-1}$ and $D^{\prime \prime}$ band at the frequency of $\sim 1520 \mathrm{~cm}^{-1}$ [40]. D band position was $1360 \mathrm{~cm}^{-1}$ with full width half maximum (FWHM) of $83 \mathrm{~cm}^{-1}$ for untreated CNTsQF. After the water plasma treatment a very small shift in the $D$ band position and FWHM of wp-CNTsQF was observed, because the treatment is mainly specific to the removal of amorphous carbon, i.e., very little etching of CNTs walls, and to the introduction of functional groups in CNTs [41]. The I $/$ $\mathrm{I}_{G}$ ratio was 1.1 for untreated CNTsQF and increases up to 1.3 for water plasma treated CNTsQF, which suggests a higher disorder in the structure of treated CNTs. After the water plasma treatment I and D" bands become more prominent. The enlargement of the D"band is in agreement with the expected attachment of polar groups on the CNTs surfaces $[42,43]$. The area of the $D$ "peak increases from 170 to 547 and the $I_{D} / / I_{G}$ ratio from 0.46 to 0.62 , for untreated CNTsQF and wp-CNTsQF, respectively.

\section{Adsorption/desorption studies}

CNTs are normally grown in the form of bundles and behave as heterogeneous sorbents. They provide four sites for the adsorption of contaminants, namely; interstitial channels, external groove sites between the bundles, external surfaces and, if the tips are open, i.e., without catalyst particles that remain on the top of each individual nanotube, internal surfaces of CNTs [22]. Since the presence of amorphous carbon reduces the adsorption/desorption efficiency of CNTs [44], it is desirable to remove it while preserving the structure of the

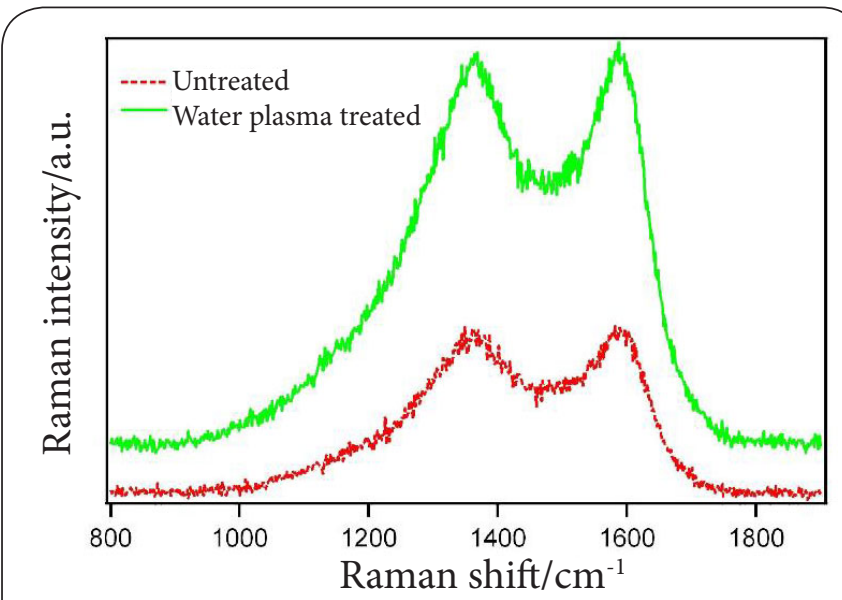

Figure 3. Raman spectra of untreated CNTsQF and WPCNTSQF.

CNTs. Here, a water plasma treatment was used to eliminate amorphous carbon. In addition, the treatment introduces oxygen functional groups and defect sites on the CNTs surface that can significantly enhance the adsorption efficiency of contaminants [45-47].

The three chlorinated compounds are non-polar solvents with a low solubility in water (i.e., hydrophobic). In particular, the water solubility values are $0.11,0.815$ and $1.4 \%$, which follow the same trend as the molecular dipole moment; $0.8,1.01$ and 2.5 D for trichloroethylene, chloroform and 1,2-dichlorobenzene, respectively.

For all the studied VOCs characteristic desorption times increased from bare QF to CNTsQF and wp-CNTsQF. The latter being the one with the longest characteristic desorption times (see Table 2).

Table 2. Characteristic desorption times of different VOCs on quartz filter, CNTsQF and plasma treated CNTsQF.

\begin{tabular}{l|lll}
\hline \multirow{2}{*}{ VOC } & \multicolumn{3}{|c}{ Filter $\tau_{1}(\mathbf{s}) / \tau_{2}(\mathbf{s})$} \\
\cline { 2 - 4 } & QF & CNTsQF & wp-CNTsQF \\
\hline trichloroethylene & $0.85 / 1.74$ & $-/ 2.38$ & $-/ 2.70$ \\
chloroform & $0.65 / 2.28$ & $0.99 / 2.32$ & $1.28 / 2.70$ \\
1,2-dichlorobenzene & $1.10 /-$ & $3.25 / 13.76$ & $-/ 15.29^{*}$ \\
\hline
\end{tabular}

* due to the small number of points, this value has a large error associated with it. However, the value fits well with the one obtained for desorption of 1,2-dichlorobenzene on $\mathrm{CNTsQF}$, and therefore, it is regarded as reliable.

In the case of trichloroethylene it was found that carbon nanotubes increase the time constant of the slow desorption mechanism $\left(\tau_{2}\right)$ (Table 2, Figure 4a), which is assumed to be mainly related to $\pi-\pi$ interactions between CNTs and the $\mathrm{C}=\mathrm{C}$ bond present in $\mathrm{C}_{2} \mathrm{HCl}_{3}[14,17]$. Due to the removal of 

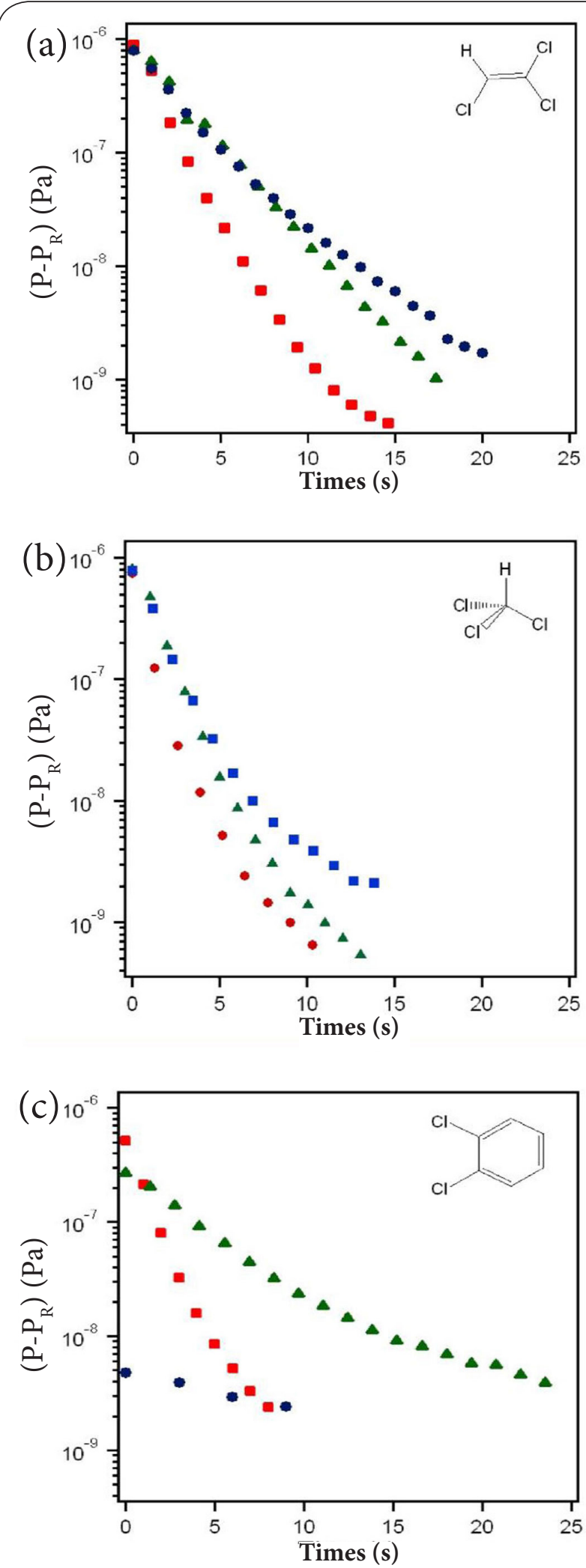

Figure 4. Comparative desorption study. Desorption process of (a) trichloroethylene, (b) chloroform and (c) 1,2-dichlorobenzene. Squares: QF, triangles: CNTsQF and circles: WPCNTsQF. amorphous carbon after the water plasma treatment, and the corresponding surface area enhancement that provides more space for solute adsorption, the desorption time of the wp-CNTsQF sample increased with respect to that of untreated CNTs (Figure 4a, Table 2). Moreover, the introduction of oxygen groups on the CNTs surface enhanced the $\pi$-EDA interactions with the VOC.

Owing to the lack of $\pi$-electrons in chloroform, the main interactions with CNTs are $\pi$-EDA and hydrogen bonding. The water solubility and dipole moment are slightly higher than for trichloroethylene and hence, the interactions are stronger and characteristic times longer (Table 2, Figure 4b). However, the total desorption time is shorter than for trichloroethylene, probably due to steric effects that avoid the adsorption of more molecules.

In comparison to the other studied VOCs, 1,2-dichlorobenzene contains an aromatic ring and combines a high polarity index with a high solubility in water. Thus, the main interactions with CNTs are supposed to be polar- $\pi$ interaction, $\pi$-stacking and hydrogen bonding. Plasma-treated CNTs without amorphous carbon and with oxygen functional groups attached on their surface increase the aromatic-aromatic interactions between 1,2-dichlorobenzene and aromatic rings present in the CNTs structure [47]. Due to the large difference in the characteristic time between bare QF and carbon nanotubes-based filters, we can assume that possibly a multilayer condensation occurs ( $\pi$-stacking interactions), which significantly increases their adsorption (Figure 4c).

From the above results it was not possible to determine the difference between the mechanisms that govern the two characteristic desorption times $\left(\tau_{1}\right.$ and $\left.\tau_{2}\right)$. Future experiments should be carried out in order to explain the observed behavior.

\section{Conclusions}

Vertically-aligned multiwall carbon nanotubes have been successfully deposited on quartz fiber filters for environmental applications. A water plasma treatment of the grown nanotubes introduces oxygen functional groups on their surface without modification of their alignment. The presence of inner cavities and functional groups on the CNTs surface contribute to improve their capability to remove or selectively detect organic pollutants. It has been proven that the adsorption/desorption capacity of chlorinated VOCs by CNTsQF and wp-CNTsQF is higher than that of bare QFs. In addition, the presented results show that CNTsQF and wp-CNTsQF affinity for the adsorption/desorption of chlorinated VOCs increases with compound solubility in water and polarity. Finally, molecules with aromatic rings present stronger interactions with CNTs ( $\pi$-stacking) and thus, significantly longer desorption times and time constants.

\section{Competing interests}

The authors declare that they have no competing interests. 
Amade et al. Journal of Environmental Engineering \& Ecological Science 2014, http://www.hoajonline.com/journals/pdf/2050-1323-3-2.pdf

Authors' contributions

\begin{tabular}{|l|c|c|c|c|}
\hline Authors' contributions & RA & SH & IRO & EB \\
\hline Research concept and design & -- & -- & - & $\checkmark$ \\
\hline Collection and/or assembly of data & $\checkmark$ & $\checkmark$ & $\checkmark$ & -- \\
\hline Data analysis and interpretation & $\checkmark$ & $\checkmark$ & $\checkmark$ & $\checkmark$ \\
\hline Writing the article & $\checkmark$ & $\checkmark$ & $\checkmark$ & -- \\
\hline Critical revision of the article & $\checkmark$ & -- & -- & $\checkmark$ \\
\hline Final approval of article & -- & -- & -- & $\checkmark$ \\
\hline Statistical analysis & $\checkmark$ & $\checkmark$ & $\checkmark$ & -- \\
\hline
\end{tabular}

Acknowledgement

This work was supported by projects 2009SGR00185 of AGAUR of Generalitat de Catalunya and CTQ2009-14674CO2-01 from MICINN of Spanish Government. The authors thank to ServeisCientifico-Tècnics of the Universitat de Barcelona (SCT-UB) for measurement facilities.

\section{Publication history}

Senior Editor: Mika Sillanpaa, Lappeenranta University of Technology, Finland.

EIC: Robert Boyd Harrison, University of Washington, USA.

Received: 17-Dec-2013 Revised: 13-Jan-2014

Accepted: 06-Feb-2014 Published: 05-Mar-2014

\section{References}

1. lijima S. Helical microtubules of graphitic carbon. Nature. 1991; 354:5658. | Article

2. Wildoer JWG, Venema LC, Rinzler AG, Smalley RE and Dekker C. Electronic structure of atomically resolved carbon nanotubes. Nature. 1998; 391:59-62. | Article

3. Salvetat JP, Kulik AJ, Monard JM, Briggs GAA, Stockli T and Metenier K et al. Elastic modulus of ordered and disordered multiwalled carbon nanotubes. Adv. Mater. 1999; 11:161-5. | Article

4. Pan ZW, Xie SS, Lu L, Chang BH, Sun LF, ZhouWY, Wang G and Zhang DL. Tensile tests of ropes of very long aligned multiwall carbon nanotubes. Appl. Phys. Lett. 1999; 74:3152-54. | Article

5. Agnihotri S, Root MJ and Abadi MR. Adsorption equilibrium of organic vapors on single-walled carbon nanotubes. Carbon. 2005; 43:23792388. | Article

6. Simon P and Gogotsi Y. Materials for electrochemical capacitors. Nat Mater. 2008; 7:845-54. | Article | PubMed

7. Amade R, Jover E, Caglar B, Mutlu T and Bertran E. Optimization of $\mathrm{MnO}_{2}$ /vertically aligned carbon nanotube composite for supercapacitor application. J. Power Sources. 2011; 196:5779-83. | Article

8. Sinha N, Ma J and Yeow JT. Carbon nanotube-based sensors. J Nanosci Nanotechnol. 2006; 6:573-90. | Article | PubMed

9. Cheng $Y$ and $Z$ hou $O$. Electron field emission from carbon nanotubes. $C$. R. Physique. 2003; 4:1021-33. | Article

10. Upadhyayula VK, Deng S, Mitchell MC and Smith GB. Application of carbon nanotube technology for removal of contaminants in drinking water: a review. Sci Total Environ. 2009; 408:1-13. | Article | PubMed

11. Long RQ and Yang RT. Carbon nanotubes as superior sorbent for dioxin removal. J Am Chem Soc. 2001; 123:2058-9. | Article | PubMed

12. Fugestsu B, Satoh S, Iles A, Tanaka K, Nishi N and Watari F. Encapsulation of multi-walled carbon nanotubes (MWCNTs) in $\mathrm{Ba}^{2+}$-alginate to form coated micro-beads and their applications to the pre-concentration/ elimination of dibenzo-p-dioxin, dibenzofuran, and biphenyl from contaminated water. Analyst. 2004; 129:565-566. | Article

13. Peng $X$, Li Y, Luan Z, Di Z, Wang H, Tian B and Jia Z. Adsorption of 1,2-dichlorobenzene from water to carbon nanotubes. Chem. Phys.Lett.

\section{3; 376:154-158. | Article}

14. Ma X, Anand D, Zhang $X$ and Talapatra S. Adsorption and desorption of chlorinated compounds from pristine and thermally treated multiwalled carbon nanotubes. J. Phys. Chem. C. 2011; 115:4552-4557. | Article

15. Su F and Lu C. Adsorption kinetics, thermodynamics and desorption of natural dissolved organic matter by multiwalled carbon nanotubes. $J$ Environ Sci Health A Tox Hazard Subst Environ Eng. 2007; 42:1543-52. I Article | PubMed

16. Sheng G, Li J, Shao D, Hu J, Chen C, Chen Y and Wang X. Adsorption of copper(II) on multiwalled carbon nanotubes in the absence and presence of humic or fulvic acids. J Hazard Mater. 2010; 178:333-40. I Article | PubMed

17. Kah M, Zhang X, Jonker MT and Hofmann T. Measuring and modeling adsorption of PAHs to carbon nanotubes over a six order of magnitude wide concentration range. Environ Sci Technol. 2011; 45:6011-7. | Article I PubMed

18. Yang $\mathrm{K}, \mathrm{Wu} \mathrm{W}$, Jing $\mathrm{Q}$ and Zhu L. Aqueous adsorption of aniline, phenol, and their substitutes by multi-walled carbon nanotubes. Environ Sci Technol. 2008; 42:7931-6. | Article | PubMed

19. Lin $D$ and Xingt $B$. Adsorption of phenolic compounds by carbon nanotubes: role of aromaticity and substitution of hydroxyl groups. Environ Sci Technol. 2008; 42:7254-9. | Article | PubMed

20. Yang $K$, Wu W, Jing $Q$, Jiang $W$ and Xing B. Competitive adsorption of naphthalene with 2,4-dichlorophenol and 4-chloroaniline on multiwalled carbon nanotubes. Environ Sci Technol. 2010; 44:3021-7. | Article I PubMed

21. Gotovac S, Hattori Y, Noguchi D, Miyamoto J, Kanamaru M, Utsumi S, Kanoh $\mathrm{H}$ and Kaneko $\mathrm{K}$. Phenanthrene adsorption from solution on single wall carbon nanotubes. J Phys Chem B. 2006; 110:16219-24. | Article | PubMed

22. Agnihotri S, Mota JP, Rostam-Abadi M and Rood MJ. Theoretical and experimental investigation of morphology and temperature effects on adsorption of organic vapors in single-walled carbon nanotubes. J Phys Chem B. 2006; 110:7640-7. | Article | PubMed

23. Hussain $C M$, Saridara $C$ and Mitra $S$. Microtrapping characteristics of single and multi-walled carbon nanotubes. J Chromatogr A. 2008; 1185:161-6. | Article | PubMed

24. Gotovac S, Song L, Kanoh H and Kaneko K. Assembly structure control of single wall carbon nanotubes with liquid phase naphthalene adsorption. Colloids and SurfacesA: Physicochem. Eng. Aspects. 2007; 300: 117-121. | Article

25. Chen J, Hamon MA, Hu H, Chen Y, Rao AM, Eklund PC and Haddon RC. Solution properties of single-walled carbon nanotubes. Science. 1998; 282:95-8. | Article | PubMed

26. Datsyuk V, Kalyva M, Papagelis K, Partgenios J, Tasis D, Siokou A, Kallitsis I and Galiotis C. Chemical oxidation of multiwalled carbon nanotubes. Carbon. 2008; 46:833-40. I Article

27. Chakrapani N, Curran S, Wei B and Ajayan PM. Spectral fingerprinting of structural defects in plasma treated carbon nanotubes. J. Mater. Res. 2003; 18:10 2515-2521. | Article

28. Hussain $S$, Amade $R$, Jover $E$ and Bertran $E$. Functionalization of carbon nanotubes by water plasma. Nanotechnology. 2012; 23:385604. | Article | PubMed

29. Hussain $S$, Amade $R$, Jover $E$ and Bertran E. Nitrogen plasma functionalization of carbon nanotubes for supercapacitor applications. J. Mater. Sci. 2013; 48:7620-7628. | Article

30. Jung YJ, Wei B, Vajtai R, Ajayan PM, Homma Y, Prbhakaran K and Ogino T. Mechanism of selective growth of carbon nanotubes on $\mathrm{SiO}_{2} / \mathrm{Si}$ patterns. NanoLett. 2003; 3:561-564. | Article

31. Atthipalli G, Epur R, Kumta PN, Allen BL, Tang Y, Star A and Gray JL. The effect of temperature on the growth of carbon nanotubes on copper foil using a nickel thin film as catalyst. Thin solid films. 2011; 519:53715375. | Article

32. Castro Smirnov JR, Jover E, Amade R, Gabriel G, Villa R and Bertran $E$. Vertically aligned carbon nanotubes for microelectrode arrays 
applications. J Nanosci Nanotechnol. 2012; 12:6941-7. | Article | PubMed

33. Gonzaga de Resende V, Antunes EF, Anderson de Oliveira L, Deiler ALO, Vladimir JTA and Evaldo JC. Growth of carbon nano tubes for eston carbon fibers with an amorphous silicon interface. Carbon. 2012; 48:3635-3658.

34. Jeon S, Lee C, Tang J, Hone J and Nuckolls C. Growth of serpentine carbon nanotubes on Quartz substrates and their electrical properties. Nano Res. 2008; 1:427-433. I Pdf

35. Li P, Zong Y, Zhang Y, Yang M, Zhang R, Li S and Wei F. In situ fabrication of depth-type hierarchical CNT/quartz fiber filters for high efficiency filtration of sub-micron aerosols and high water repellency. Nanoscale. 2013; 5:3367-72. I Article I PubMed

36. Wu W, Chen W, Lin D and Yang K. Influence of surface oxidation of multiwalled carbon nanotubes on the adsorption affinity and capacity of polar and nonpolar organic compounds in aqueous phase. Environ Sci Technol. 2012; 46:5446-54. | Article | PubMed

37. Ferrari CF. Determination of bonding in diamond like-carbon by Raman spectroscopy. Diam.Relat. Mat. 2002; 11:1053-1061. | Pdf

38. Bacsa WS, Ugarte D, Chatelain A and de Heer WA. High-resolution electron microscopy and inelastic light scattering of purified multishelled carbon nanotubes. Phys Rev B Condens Matter. 1994; 50:15473-15476. | Article I PubMed

39. Oswald S, Havel M and Gogotsi Y. Monitoring oxidation of multiwalled carbon nanotubes by Raman spectroscopy. J. Raman Spectrosc. 2007; 38:728-36. | Article

40. Cuesta A, Dhamelincourt P, Laureyns J, Martinez-Alonso A and Tascon JMD. Raman microprobe studies on carbon materials. Carbon.1994; 32:1523-1532. | Article

41. Reich S, Thomsen C and Maultzsch J. Carbon Nanotubes: Basic Concepts and Physical Properties. Weinheim: Wiley-VCH. 2004; 224. I Article

42. Ramos SC, Vasconcelo C, Antunes EF, Lobo AO, Trava-Airoldi VJ and Corat EJ. Wettibility controlon vertically aligned multiwalled-carbon nanotube surfaces with oxygen pulsed DC plasma and $\mathrm{CO}_{2}$ laser treatments. Diam. Relat. Mat. 2010; 19:752-755. I Article

43. Lobo SC, Ramos SC, Antunes EF, Marciano FR, Trava-Airoldi VJ and Corat EJ. Fast functionalization of vertically aligned multiwalled carbon nanotubes by oxygen plasma. Mat. Lett. 2012; 70:89-93. I Article

44. Yang $\mathrm{K}$ and Xing $\mathrm{B}$. Desorption of polycyclic aromatic hydrocarbons from carbon nanomaterials in water. Environ Pollut. 2007; 145:529-37. | Article I PubMed

45. Chakrapani N, Zhang YM, Nayak SK, Moore JA, Carroll DA, Choi YY and Ajayan PM. Chemisorption of acetone on carbon nanotubes. J. Phys. Chem. B. 2003; 107:9308-9311. I Article

46. Zhou LG and Shi SQ. Adsorption of foreign atoms on stone-walls defects in carbon nanotubes. Carbon. 2003; 41:579-625. | Article

47. Pan B and Xing B. Adsorption mechanisms of organic chemicals on carbon nanotubes. Environ Sci Technol. 2008; 42:9005-13. | Article | PubMed

\section{Citation:}

Amade R, Hussain S, Ocaña IR and Bertran E.

Growth and functionalization of carbon nanotubes on quartz filter for environmental applications.

J Environ Eng Ecol Sci. 2014; 3:2.

http://dx.doi.org/10.7243/2050-1323-3-2 